\title{
Sexualidade e educação: uma comparação entre alunos surdos e não surdos
}

\section{Sexuality and education: a comparison between students not deaf and deaf}

\author{
${ }^{1}$ Victor Hugo de Oliveira Henrique hugo31_oh@hotmail.com \\ ${ }^{2}$ Alex Sandro Henrique de Jesus Freitas \\ ${ }^{3}$ Edna Lopes Hardoim
}

\section{RESUMO:}

Diferente dos alunos ouvintes, as dúvidas sobre sexualidade de alunos surdos não são esclarecidas em uma palestra e nem em sala de aula. Objetivando conhecer a concepção de sexualidade de alunos surdos e não surdos e saber como a expressam, foi realizada uma entrevista semi-estruturada usando recursos visuais, com os alunos do $3^{\circ}$ Ano do EM do Programa EJA no CEAADA e de uma Escola Municipal. Os dados evidenciam que o preservativo é o método contraceptivo mais utilizado por ambos os grupos entrevistados. Entre os alunos surdos não há um diálogo muito amplo sobre sexualidade com a família, diferente dos alunos surdos, a maioria respondeu que o diálogo é mais amplo com o parceiro/a. Quanto a realização de atividades na escola, entre os alunos surdos é unânime a necessidade de aulas de educação sexual, e entre os alunos não surdos, uma minoria foi contrária a ideia. Para a maioria dos alunos surdos a sexualidade está relacionada com o ato de fazer sexo, evidenciando a importância de atividades sobre a temática sexualidade, para esclarecer realmente o que compõe a sexualidade. Foi possível evidenciar que os surdos conseguem vivenciar sua sexualidade como qualquer outro indivíduo não surdo.

Palavras-chave: Sexualidade. Educação. Alunos surdos.

\section{ABTRACT:}

Different of hearing students, doubts about sexuality deaf students are not clarified in a lecture and not in the classroom. Order to know the conception of sexuality deaf students and deaf and does not know how to express, a semi-structured interview using visuals was held with students of the 3rd year of high school of program EJA in CEAADA and a municipal school.The data show that the condom is the contraceptive method most used by both groups interviewed. Among the deaf students there is not a very broad dialogue about sexuality with family, different from deaf students, most replied that dialogue is wider with the partner / a. As for carrying out activities in school, among deaf students is unanimous the need for sex education classes, and among non-deaf students, a minority was against the idea. For most deaf students sexuality is related to the act of having sex, showing the importance of activities on the theme sexuality, to really clarify what makes up sexuality. The results showed that deaf people can experience their sexuality as any other individual not deaf.

Keywords: Sexuality. Education. Deaf students.

\footnotetext{
Graduado em Ciências Biológicas -IB/UFMT, Mestrando em Educação - IB/UNESP.

Graduado em Ciências Biológicas - IB/UFMT, Mestrando em Ciências Biológicas (Botânica) - INPA.

Professora e Doutora do Departamento de Botânica e Ecologia - IB/UFMT.
} 


\section{INTRODUÇÃO}

O processo de ensino-aprendizagem inicia-se quando há uma apropriação dos alunos referente a um determinado assunto abordado pelo docente, que possui um papel importante nesta relação. O professor deve proporcionar algumas condições necessárias neste processo, especialmente no que diz respeito às estratégias de que se utilizará para efetivar a transposição didática do tema, ou seja, estratégias metodológicas que irá facilitar o entendimento do conhecimento científico, associando-o ao cotidiano do aluno. O saber acadêmico serve de base para legitimar o saber ensinado, cuja mediação é feita pelo professor (RODRIGUES E SCHEID, 2008).

Abordar a temática da sexualidade não é uma tarefa fácil, em muitos casos, a família simplesmente se silencia sobre o tema por medo ou por não terem as informações necessárias, como se isso fosse estimular excessivamente a sexualidade dos filhos, fazendo com que as dúvidas referentes ao tema sejam trabalhadas na escola. A escola, na maioria das vezes, não está preparada, embora esse seja um dos temas transversais propostos pelos Parâmetros Curriculares Nacionais a ser trabalhado na educação básica. Ainda hoje, o que se vê, são propostas não bem elaboradas, com professores trabalhando a sexualidade apenas quando surge algum "problema”, como gravidez na adolescência ou algum estudante com DST (RODRIGUES E SCHEID, 2008).

No decorrer dos anos, percebeu-se que a educação Sexual obteve um inegável desenvolvimento e no âmbito escolar, tornando-se uma medida muito significativa para desconstruir diversos mitos e preconceitos que foram sendo e ainda são produzidos na escola. Desse modo, os/as docentes precisam se preparar para abordar e discutir estes e outros temas de extrema relevância social (SOUZA; SANTOS, 2012).

A Educação Sexual pode ser desenvolvida com base nos Parâmetros Curriculares Nacionais. De acordo com os PCN, os trabalhos referentes a educação sexual devem ser realizados em três eixos norteadores, são eles “corpo: matriz da sexualidade", "prevenção de doenças sexualmente transmissíveis" e "relações de gênero" (BRASIL, 1997).

Dentro da educação sexual, aborda-se a sexualidade, que está presente em todas as faixas etárias, ela pode ser compreendida por meio de aspectos biológicos, psicológicos e socioculturais e corresponde um conjunto de concepções e valores que envolvem a intencionalidade humana e a expressão afetiva de cunho social e histórico.

A sexualidade envolve, então, uma amplitude de condutas humanas, para além de sua genitalidade e não deve ser entendida, exclusivamente, como sinônimo de sexo, relação sexual, orgasmo, órgãos sexuais, mas sim, na sua dimensão ampla e cultural que abrange diferentes sentidos, como o amor, relacionamentos afetivos e sexuais, a sensualidade, o erotismo e o prazer, a expressão da identidade e dos papéis sexuais. Ela inicia-se a partir das primeiras experiências afetivas do bebê com os pais ou com qualquer outra pessoa que esteja em constante contato com ele (MAIA; ARANHA, 2005).

A sexualidade envolve não apenas a conduta sexual do indivíduo, o ato sexual e a reprodução, mas também, tudo aquilo que remete às situações que nos proporcionam prazer, como os afetos, desejos, a nossa relação com o próprio corpo, as relações interpessoais, bem como o papel sexual que a pessoa exerce (SCHLIEMANN, 2005)

Percebe-se então, que a sexualidade faz parte sociedade, é uma questão de cidadania. Neste sentido, o entendimento da sexualidade deve proporcionar uma reflexão voltada para as múltiplas formas de manifestações humana e o lugar que estas manifestações ocupam em nossa sociedade, como o sexo, o desejo, o medo, o amor, o corpo biológico e os papéis sócias/sexuais. 
No passado falar de sexualidade dentro do contexto da escola com os alunos era um afronto para a sociedade e o professor era punido de alguma forma. Com isso, questões sobre sexualidade do aluno era omitida dentro da instituição escolar. Segundo TIBA (1994):

\begin{abstract}
"Durante muito tempo, a sexualidade foi solenemente ignorada pelas escolas. Os professores agiam como se seus alunos fossem seres assexuados, mesmo quando chegavam à adolescência. Não podia ser diferente; afinal, toda sociedade o tema sexo entre quatro paredes. O melhor método, portanto era não tocar no assunto e deixar que a natureza se encarregasse de ensinar os alunos o que estava se passando. E como a ordem era reprimir a sexualidade, melhor seria não tocar no assunto para não despertá-la”.
\end{abstract}

Notadamente observa-se que durante anos o tabu, o preconceito, o medo, o despreparo e os mitos tomavam conta do tema sexualidade, e que a escola, especificamente, os professores camuflavam o assunto com as censuras sublimadas. Toda sociedade repudiava qualquer tentativa de insipiência no tocante desse assunto, que deveria ser reprimido para não corromper os adolescentes. Assim, essa cultura assolou de geração a geração.

Atualmente vivemos em uma época de excessos de estímulos sexual em que a mídia promove certo incentivo para o ato sexual sem dar a mínima noção de segurança. A questão moral está hoje obscurecida por inquietações sobre o impacto do sexo na qualidade de vida do indivíduo. A televisão, o cinema, a imprensa, a propaganda, inundando o cotidiano dos jovens com apelos sexuais jamais vistos por outra geração. E é daí que nasce a fantasia de que toda relação sexual é maravilhosa; visto que o adolescente se deixa influenciar por esse bombardeio. Por este princípio, percebe-se que o espaço da escola deve ser valorizado para se discutir questões em torno da sexualidade, não como controladora da vontade do sujeito, mas, como instância propiciadora de reflexão sobre a temática.

É importante que o professor expanda seus conhecimentos acerca do assunto, objetivando de auxiliar os alunos que não possuem informações adequadas, respondendo às dúvidas de forma esclarecedora, respeitando a opinião de cada educando. Se o educador não for preparado e não possuir informações adequadas, poderá transportar seus valores, crenças e opiniões como verdades absolutas, não permitindo aos alunos a autonomia para desenvolver seu conhecimento (RODRIGUES; WECHSLER, 2014).

É preciso que os (as) docentes assumam o desafio de garantir a todos os alunos o direito a uma educação de qualidade, que não pode ser prejudicada seja pela cor da pele, orientação sexual, identidade de gênero, entre outros fatores.

O professor como um agente importante no processo de ensino-aprendizagem, precisa desenvolver estratégias metodológicas para trabalhar diferentes temas dentro de sela de aula, e para isso ele precisa saber a concepção dos alunos sobre esses temas, visando isso, a pesquisa objetivou compreender a concepção de sexualidade de alunos surdos e não surdos e saber como a expressam, fazendo com que a partir dos resultados, os professores possam elaborar estratégias metodológicas para trabalhar essa temática nas escolas.

\title{
2 SEXUALIDADE E SURDEZ
}

A temática sexualidade dentro da escola, muitas vezes é delega ao professor de Ciências e/ou de Biologia o papel de orientador sexual, trabalho que deveria ser de toda a comunidade escolar, conforme prevêem os temas transversais dos PCNs (BRASIL, 1997).

Como os conteúdos a serem trabalhados são muitos, e as escolas, em sua maioria, não têm um projeto multidisciplinar para trabalhar essa temática, a sexualidade acaba sendo abordada nas aulas de Biologia e/ou de Ciências, que trabalham apenas os aspectos biológicos, tais como aparelho reprodutor masculino e feminino, os 
órgãos sexuais, as DST's e os métodos contraceptivos, sem trabalhar os aspectos psicológicos e socioculturais (RODRIGUES E SCHEID, 2008).

Diferente da sexualidade dos adolescentes tidos como normais, a sexualidade dos deficientes não é um tema esclarecido nas salas de aula e nem é comumente tido como assunto de debates ou palestras.

Quando se trata de sua expressão por pessoas surdas, normalmente, o que acontece é a desconsideração. Professores e profissionais de saúde não têm desenvolvido competência para lidar com essa temática, sobretudo, quando se refere às pessoas com necessidades especiais.

A história da humanidade, assim como a história dos deficientes, varia de cultura para cultura, refletindo crenças, valores e ideologias que, materializadas em práticas sociais, estabelecem modos diferenciados de relacionamentos entre deficientes e não-deficientes. Em uma visão histórico-cultural, a família tende a imprimir, geralmente, aos portadores de deficiências, a ideia de que são incapazes, inábeis, inseguros e assim vão sendo "educados" para serem indefesos, dependentes e até considerados por alguns como assexuados e desinteressantes, interferindo no modo de expressar e vivencias sua sexualidade (MACEDO et al. 2009).

A capacidade de manifestar e sentir amor constitui a essência básica da sexualidade. Demonstrações de ternura, simpatia e atração exprimem amor e afeto e revelam a natureza do indivíduo com ser sexuado.

Em geral, pessoas com deficiência são privadas de orientação sexual e é essa desinformação geral que estimula o preconceito e restringe o direito dessas pessoas ao exercício de uma vida sexual livre, plena e satisfatória. Na adolescência, as pessoas com deficiência anseiam pelo estabelecimento de uma relação amorosa, afetiva e sexual, uma vez que estão expostas às mesmas normas sociais que as não-deficientes (MAIA; ARANHA, 2005).

Diversos autores têm defendido que toda pessoa com deficiência é uma pessoa íntegra na sua sexualidade. Isto é, independentemente das possíveis limitações e complicações que possam ocorrer na manifestação sexual, ninguém se torna assexuado em função de uma incapacidade física, sensorial ou mental (BUSCAGLIA, 1997; MAIA; ARANHA, 2005).

Sendo assim, uma pessoa não pode ser considerada assexuada, pois a sexualidade é inerente ao ser social. Há duas décadas, a literatura vem apontando a sexualidade do deficiente como angelical, infantil ou como agressiva e incontrolável. Nesse sentido os deficientes são vistos sob duas premissas: os de anjos, quando a sexualidade é reprimida e não manifesta e os de feras, quando é expressa explícita e inadequadamente. Porém nesses dois casos há uma percepção distorcida sobre a vida afetiva e sexual dessas pessoas (PINHEIRO; LEAL, 2005).

Ao falar sobre o tema sexualidade e deficiências, o mais importante é lembrar que ter vontades e desejos são coisas comuns a todo o ser humano, bem como suas necessidades de satisfação. A atividade sexual pode ser vista como uma forma de busca por segurança e proteção (MACEDO et al. 2009).

\section{METODOLOGIA}

A coleta de dados teve início após a aprovação do projeto pelo Comitê de Ética em Pesquisa em Seres Humanos (Parecer número 1.426.274),

Foi realizada uma entrevista semi-estruturada a quinze alunos surdos, utilizando recursos visuais, ou seja, a Linguagem Brasileira de Sinais (LIBRAS) e filmadora. Os alunos eram do $3^{\circ}$ Ano do Ensino Médio do Programa Educação para Jovens e Adultos (EJA) no Centro Estadual de Atendimento e Apoio ao Deficiente Auditivo (CEAADA) e a 15 alunos, também do $3^{\circ}$ Ano do Ensino Médio, de uma Escola Municipal de ensino regular. 
Optou-se pela entrevista semi-estruturada que, de acordo com Lüdke e André, (1986, p.34) é considerada uma ótima ferramenta para a coleta de dados em trabalhos de pesquisa em educação, pois podem dar uma liberdade maior ao entrevistador, já que é aplicada “a partir de um esquema básico, porém não aplicado rigidamente, permitindo que o entrevistador faça as necessárias adaptações”.

Todos os estudantes que participaram da pesquisa preencheram o Termo de Consentimento Livre e Esclarecido para participação na pesquisa, uso da imagem, voz e textos com fins de divulgação científica

Foram questionados sobre diferentes aspectos da temática sexualidade, tais como, idade para começar um relacionamento, para ter a primeira relação sexual, personalidade dos alunos, uso de métodos contraceptivos, interferência da família na expressão da sexualidade, meios de buscar informações sobre o tema e atividades que gostariam que fossem desenvolvidas nas escolas.

\section{RESULTADOS E DISCUSSÃO}

A maior quantidade de alunos não surdos possui menos de 18 anos, já entre os alunos surdos a faixa etária se concentra acima dos 30 anos de idade (Tabela 1), evidenciando que o aluno surdo, entra na escola mais tardiamente. Talvez por uma pseudoproteção da família, que interfere, assim, no processo dinâmico de participação das pessoas no contexto relacional, legitimando sua interação nos grupos sociais, possibilitando a ampliação de sua percepção de mundo e permitindo expressão.

Tabela 1 - Idade dos sujeitos da pesquisa

\begin{tabular}{ccc}
\hline IDADE & NÃO SURDOS & SURDOS \\
\hline Abaixo de 18 & 5 & - \\
$18-20$ & 3 & 1 \\
$21-25$ & 1 & 3 \\
$26-30$ & 2 & 5 \\
Acima de 30 & - & 6 \\
Não responderam & 4 & - \\
Total & 15 & 15 \\
\hline
\end{tabular}

Fonte: ?

O desejo e as descobertas da sexualidade são sinais de saúde. Mas quando o adolescente com deficiência começa a sair, a conhecer pessoas, namorar e buscar uma vida sexual ativa, a família perde o controle sobre suas atividades, o que pode gerar medo de que ele seja rejeitado ou até mesmo abusado sexualmente. Com o intuito de proteger os filhos com deficiência, os pais costumam tratá-los como eternas crianças, negando assim o seu direito de expressar sua sexualidade (MACEDO et al. 2009).

\footnotetext{
"A sensação da mudança do corpo de criança para adolescente traz conflitos para o jovem, que antes tinha controle sobre seu corpo e, é preciso aprender a lidar não apenas com ele, mas também com o desejo e a nova sexualidade que desponta desencadeia pensamentos, sensações e, consequentemente, comportamentos que provocam um turbilhão de dúvidas e de emoções até então desconhecidas.” (HARDOIM; MIYAZAKI., 2012).
}

Com relação ao sexo dos sujeitos da pesquisa, tanto entre os alunos não surdos quanto entre os alunos surdos sujeitos da pesquisa, houve uma predominância do sexo masculino- 9 do grupo não surdo e 8 dos surdos; um ouvinte não respondeu. Os respondentes de ambas as categorias, em sua maioria, se auto-afirma heterossexual (Tabela 2). 
Tabela 2 - Orientação Sexual informada pelos sujeitos da pesquisa

\begin{tabular}{ccc}
\hline & Não surdos & Surdos \\
\hline Heterossexual & 11 & 14 \\
Homossexual & 1 & 1 \\
Não responderam & 3 & - \\
Total & 15 & 15 \\
\hline
\end{tabular}

Fonte: ?

Quando perguntados sobre qual a idade ideal para se iniciar um namoro, entre os alunos ouvintes houve uma predominância entre 15- 18 anos de idade, enquanto que entre os alunos surdos a melhor idade é em torno de 19-20 anos). Já com relação à idade adequada para a primeira relação sexual os dados se assemelham, observando-se que para a maioria dos alunos não surdos a melhor idade está entre os 15-18 anos, ou seja, a partir do momento que iniciou um namoro já é possível ter relações sexuais. Todavia, os alunos surdos acham, em sua maioria, que a idade certa para a primeira relação sexual é acima dos 25 anos de idade (Tabela 3).

Tabela 3 - Idade informada pelos sujeitos da pesquisa para começar a namorar e ter relações sexuais

\begin{tabular}{ccccc}
\hline \multirow{2}{*}{ Idade } & \multicolumn{2}{c}{ Namorar } & \multicolumn{2}{c}{ Praticar sexo } \\
& Não Surdos & Surdos & Não Surdos & Surdos \\
\hline Abaixo de 15 & 3 & 3 & - & - \\
$15-18$ & 9 & 3 & 8 & 3 \\
$19-20$ & 2 & 5 & 2 & 3 \\
$21-25$ & - & 3 & - & 7 \\
Mais de 25 & - & 1 & - & 1 \\
Após o casamento & - & - & 3 & - \\
Não responderam & 1 & - & 15 & 15 \\
Total & 15 & 15 &
\end{tabular}

Generalizar a intencionalidade das pessoas para iniciar a prática sexual é abrir um campo para equívocos e até preconceitos, cerceando a liberdade individual de manifestar suas diferenças. Para uma pessoa com deficiência, a descoberta do corpo e do prazer em manipulá-lo pode ocorrer tardiamente. Na puberdade quando o corpo já está desenvolvido, os deficientes podem manifestar inadequadamente as condutas sobre seu corpo e como manipulá-lo por falta de aprendizado, o que pode levá-los à ansiedade e a sofrer repressões sociais. Com o avanço da idade a socialização e a interação com outras pessoas podem ficar ainda mais restritas e limitadas ao ambiente familiar.

Para Macedo et al. (2009) tal situação evidencia a importância de trabalhar a temática sexualidade nas escolas, mas para isso, é necessário um preparo de toda a comunidade escolar. Talvez uma forma seja por meio da comunicação total, defendida por Ciccone (1990), que implica em uma completa liberdade na prática de quaisquer estratégias, que permitam o resgate da comunicação, total ou parcialmente, com o surdo. Seja pela linguagem oral, língua de sinais, datilologia, pela expressão corporal e facial, ou ainda, pela combinação desses modos, o que importa é aproximar as pessoas e permitir contatos.

Acreditamos, assim como Flores (2004), que a educação para uma saúde sexual e livre expressão da sexualidade, é uma das instâncias que poderão responder à necessidade de transformação social, dado seu pa- 
pel da educação como de transmissora do conhecimento, formadora do pensar e responsável pela mudança de comportamentos.

Conversas sobre sexualidade é maior entre amigos nos surdos enquanto entre os não surdos existe um diálogo maior com o parceiro/a, e uma minoria conversa com os pais sobre o tema, evidenciando um distanciamento da família na discussão do assunto (Tabela 05). Dentre a comunidade surda, os pais acham que seus filhos deficientes são incapazes de expressar a sua sexualidade, negligenciando diálogo com os mesmos sobre sexualidade, fazendo com eles recorram aos seus amigos (MACEDO et al. 2009).

Quando questionado sobre a personalidade, a maioria dos alunos não surdos se intitula tímida (nove alunos), calmos (três alunos), com relação à liderança e atirados (1 aluno cada), os dados se assemelham com os alunos surdos, onde a maioria se diz calma e tímida (cinco alunos cada categoria), seguido de atirado e líder (três alunos cada) e por último nervoso/ansioso (um aluno). Esses dados ajudam a interpretar os dados da Tabela 04, o fato de a maioria dos alunos, tanto surdos, se considerarem tímidos, faz com que eles se interrelacionem melhor com seus amigos, já que a família não orienta muito seus filhos nesta temática. Todavia essa atitude não tem sido exclusiva do surdo, mas também de ouvintes. Dada a relevância do tema, acreditamos que deva haver clara discussão sobre a temática entre adultos e adolescentes inexperientes.

A maioria dos alunos surdos (11) e dos não surdos (12 alunos) está satisfeita com o corpo que possuem. Dentre as atividades que mais gostariam que tivesse na escola, entre os alunos não surdos, a maioria gostaria de palestras sobre sexualidade (sete alunos), seguido de filme com debates e aulas de educação sexual (quatro alunos cada). Com os alunos surdos houve um empate entre palestras e filmes com debates (seis alunos cada), seguido de aula sobre educação sexual (3 alunos). Referente a aulas de educação sexual na escola, a grande maioria dos alunos surdos concordam que deve ter (doze alunos) e apenas 3 alunos discordam. Já entre os alunos não surdos, foi unânime, todos concordam que deve ter aulas de educação sexual na escola. A pequena resistência de alguns alunos surdos em não ter aulas de educação sexual na escola pode se dar pela idade, pois a maioria possui mais de 25 anos de idade e alguns ainda conservam certos valores e acham que o assunto não se deve aprender na escola. (Tabela 5)

Tabela 4 - Fala sobre Sexualidade? Com quem?

\begin{tabular}{ccc}
\hline & Não surdos & Surdos \\
\hline Sim, com meus pais & 1 & 2 \\
Sim, com meus amigos & 3 & 9 \\
Sim, com meu/minha parceiro/a & 6 & 3 \\
Sim, com profissionais do assunto & - & - \\
Não & 4 & 1 \\
Não responderam & 1 & - \\
Total & 15 & 15 \\
\hline
\end{tabular}

Fonte: ?

Tentar compreender as relações humanas e as sexualidades por meio de filmes, sejam eles quais forem, desde que abordem o assunto, não é algo simplório, dada a dimensão da temática e grande falta de informação que afeta a muitas pessoas. É importante, e preciso, o entendimento da dimensão do tema, e que os assuntos abordados dentro da sexualidade estão ficando cada vez mais diversificados.

Pensando nisso, o cinema entra como uma alternativa simples, todavia sem deixar de ser sério e crítico, de abordar aspectos pontuais relacionados às diversas manifestações da sexualidade (CHASKO E PREVIATO, 2013). 
No caso do uso do cinema para a formação e informação acerca das questões da sexualidade, diversidade sexual e de gênero, os participantes "são capazes de se identificar com o drama, sofrer com o personagem (...), pois o sofrimento e as alegrias no filme representado dizem respeito à condição humana.” (ARAUJO; VOSS, 2009).

Tabela 5 - Atividades que gostariam que fossem desenvolvidas na escola

\begin{tabular}{ccc}
\hline Atividade & Não surdos & Surdos \\
\hline Palestras & 7 & 6 \\
Filmes com debates & 4 & 6 \\
Aula sobre Educação Sexual & 4 & 3 \\
Não responderam & - & - \\
Total & 15 & 15 \\
\hline
\end{tabular}

Fonte: ?

Apesar da maioria dos surdos não discutir sobre sexualidade com a família, eles concordam que a influência da família influencia na forma de viver sua sexualidade (sete alunos), pelo fato de ainda conservarem certos valores. Valores morais são as coisas aprendidas como direitas ou erradas, desejáveis ou indesejáveis, de acordo com os costumes da cultura em que estamos inseridos. Os valores morais são reforçados pelo exemplo de pais, parentes, e, em alguns exemplos, pela lei. Para Pozza (2010):

Relacionado aos valores distorcidos na educação sexual, podem surgir tabus, mitos, medos, desinformação, conflitos, preocupação, pseudoesclarecimentos, pseudoaceitação das questões sexuais, banalização e vulgarização da sexualidade, prostituição infantil, abuso sexual, pornografia e o moralismo.

A consciência do uso de métodos contraceptivos é bem forte, tanto entre os alunos surdos quanto entre os ouvintes. Os alunos surdos sempre quando questionados sobre esse tema, citavam o cuidado para não engravidar ante do tempo e com a AIDs, a maioria faz uso do preservativo (oito alunos) seguido da pílula (cinco alunos) e dois alunos são virgens, ou seja, nunca tiveram relações sexuais e, consequentemente, não fazem uso de métodos contraceptivos. A maioria dos alunos ouvintes também faz uso do preservativo (9 alunos), seguido da pílula, dois de cada grupo de sujeitos não fazem uso de método algum e dois alunos não responderam.

A fonte de informações mais usadas pelos surdos sobre sexualidade é a TV (oito alunos), seguido do professor (três alunos) e depois revistas e amigos (dois alunos cada), com os alunos não surdos a maior fonte de pesquisa é a internet (5 alunos), depois amigos (4 alunos), revistas (quatro alunos) e a família (dois alunos).

As idéias defendidas por Vygotsky (1989) refutam a teoria de que crianças com alguma deficiência ou cujo desenvolvimento foi impedido por um "defeito" não possam ter oportunidades semelhantes às de outros indivíduos. O aluno surdo não é simplesmente uma pessoa menos desenvolvida do que seus pares, mas alguém que se desenvolve de modo diferente, o que não implica numa percepção de mundo ou de si mesmo diferente. $\mathrm{O}$ autor afirma que os problemas dos sujeitos com deficiência não são de cunho biológico, mas, sobretudo, social. Assim, também, a natureza dos processos compensatórios para o desenvolvimento do aluno com deficiência deve ser social e não biológico.

Para o professor, tratar esta temática abordada - a sexualidade, pode se tornar ainda mais difícil quando o público alvo de nossa orientação está composto de pessoas surdas, visto que se somam duas dificuldades: a abordagem do tema que, em geral, está revestido de mitos e tabus, além do fato das dificuldades de comunicação existentes entre surdos e ouvintes. 


\section{CONSIDERAÇÕES FINAIS}

Conclui-se que os alunos surdos, muitos não sabem diferenciar sexualidade de relação sexual. Quando questionados sobre aulas de educação sexual e sexualidade na escola, a maioria foi contra, mas quando se especificava sobre DSTs e Preservativos, eles mudavam de ideia.

É necessário trabalhar também com os professores e averiguar se estão ou não realmente trabalhando esse tema na sala de aula e a metodologia do trabalho.

A pesquisa foi importante para saber o conhecimento prévio dos alunos surdos e não surdos e desmistificar alguns tabus quanto a sexualidade de deficientes, mas é necessário criar metodologias especificas para trabalhar a sexualidade com os alunos, independente de haver deficiência ou não.

Entendemos que nossa caminhada na busca de um modelo educativo, que diminua as dificuldades de compreensão dos surdos quanto a esta temática, ainda será longa, mas certamente um grande passo para resgatar a este grupo o direito à liberdade para pensar livremente e assumir idéias de acordo com sua própria convicção. A base para esses trabalhos, sem dúvida, é a pesquisa. Embora muito mais mudanças sejam necessárias para incluir o surdo na sociedade, espera-se que a educação sexual possa ser uma chave para reduzir o risco de rupturas nas famílias, o aumento da autoconfiança, e o encorajamento nos relacionamentos.

\section{REFERENCIAS}

ARAUJO, A. R.; VOSS, R. C. R. Cinema em sala de aula identificação e projeção no ensino/aprendizagem da Língua Inglesa. Conexão - Comunicação e Cultura, UCS, Caxias do Sul, v. 8, n. 15, jan./jun. 2009.

BRASIL. Secretaria de Educação Fundamental. Parâmetros curriculares nacionais: introdução aos parâmetros curriculares nacionais / Secretaria de Educação Fundamental. - Brasília: MEC/SEF, 126p. 1997.

BUSCAGLIA, L. Os deficientes e seus pais: um desafio ao aconselhamento. 3. ed. Rio de Janeiro: Record, 1997.

CHASKO, J.; PREVIATO, R.; Mostra de Cinema da Diversidade Sexual em Cascavel: Cinema em ambiente escolar. In. XI Encontro Nacional Universitário sobre Diversidade Sexual. Matinhos. Anais... Matinhos/PR UFPR. 2013;

CICCONE, M. Comunicação Total. Rio de Janeiro: Cultura Médica. 1990.

CRUZ, A. C.; OLIVEIRA, S. M. P. Sexualidade do adolescente: Um Novo Olhar sem Mitos e Preconceitos. Monografia (Graduação em Pedagogia - UNAMA) Belém/PA, 2002.

FLORES, Ainda Mair Prado. Sexualidade: representações de professores do Ensino Médio. Dissertação (Mestrado em Educação - UFSM). Santa Maria/RS, 2004.

GESUELI, Z. M. A criança surda e o conhecimento construído na interlocução em língua de sinais. Tese (Doutorado em Educação) - Universidade Estadual de Campinas: UNICAMP, Campinas, 1998.

HARDOIM, E. L.; MIYAZAKI, R.S. Saúde e Sexualidade. Cuiabá: UAB/UFMT, 2012.

HEILBORN, M. L.; AQUINO, E. M. L.; BOZON, M.; KNAUTH, D.R.; (Org.). O Aprendizado da Sexualidade. Rio de Janeiro: Garamon e Fiocruz. 2006. 
LÜDKE, M.; ANDRÉ, M. E. Pesquisa em educação: abordagens qualitativas. 5 a edição. São Paulo: Editora Pedagógica e Universitária, 1986. 123p.

MACEDO. F. N.; TERRASSI, E.P.; Sexualidade de adolescentes portadores de diferentes deficiências. In DÍAZ, F.; BORDAS, M.; GALVÃO, N; MIRANDA, T.; (Org.) Educação inclusiva, deficiência e contexto social: questões contemporâneas. - Salvador: EDUFBA, 2009.

MAIA, A. C.; ARANHA, M. S. Relatos de professores sobre manifestações sexuais de alunos com deficiência no contexto escolar. Interação em Psicologia, São Paulo, v. 9, n. 1, p. 103-116, 2005.

PINHEIRO, A. L.; LEAL, I. Sexualidade na deficiência mental. Revista Integrar, 2005.

POZZA, P. Sexualidade e valores. Disponível em: <http://www.notisul.com.br/n/colunas/sexualidade_e valores-26196> Acessado em Agosto de 2014

RODRIGUES, C. P.; WECHSLER, A. M.; A sexualidade no ambiente escolar: a visão dos professores de educação infantil. Cadernos de Educação: Ensino e Sociedade, Bebedouro-SP, 1 (1): 89-104, 2014.

RODRIGUES, L. R.; SCHEID, N. M. J.; Os conhecimentos básicos que os adolescentes possuem sobre sexualidade e o papel do professor de Biologia neste contexto. Educação, v. 33, n. 3, set/dez. 2008.

SCHLIEMANN, A. P. Sexualidade - adolescência - deficiência mental: um desafio a pensar. In. Simpósio Internacional do Adolescente, 2., 2005. São Paulo. Anais... São Paulo: Faculdade de Psicologia da PUC/SP Departamento de Psicologia do Desenvolvimento, 2005.

SILVA, A. M. Educação especial e inclusão escolar: história e fundamentos. $1^{\text {a }}$ ed. Curitiba: Ibpex, 2010.

SOUSA, E.; SANTOS, C.; Educação Sexual na Escola: Descontruindo mitos e preconceitos acerca da sexualidade, gênero e diversidade sexual. In. VI Colóquio Internacional "Educação e Contemporaneidade". Anais... SE/Brasil. 2012.

SOUZA, L. L.; ROCHA, S. A. (Org). Formação de educadores, gênero e diversidade. Cuiabá: EdUFMT, 2012.

SOUZA, L. L.; SALGADO, R. G. Infância e juventude no contexto escolar: gêneros e sexualidades em debate. Cuiabá: EdUFMT, 2012.

TIBA, I.; Adolescência: O despertador do sexo. São Paulo: Ed. Cortez, 1994

VYGOTSKY, Lev S. Fundamentos de defectologia. Obras completas - tomo cinco. Havana: Editorial Pueblo y Educación, 1989. 